\title{
DIGITALISASI DESA UNTUK MENINGKATKAN KUALITAS LAYANAN DAN INFORMASI
}

\author{
Siti Asmaniyah Mardiyani ${ }^{1}$, Desy Nofita Sari ${ }^{2}$, Suhartini Koti ${ }^{3}$, Ririn Cahyati2 \\ Hardianti Safitri ${ }^{4}$, Mahmud Abdul Aziz ${ }^{2}$, Buchori Muslim4 ${ }^{4}$ Andre Afriadi5 ${ }^{5}$, Diki Heru \\ Frandika6, Didit Hendrawan' ${ }^{5}$, Panji Eka Sukmana ${ }^{4}$ \\ ${ }^{1}$ Fakultas Pertanian, Universitas Islam Malang \\ ${ }^{2}$ Fakultas Keguruan dan Ilmu Pendidikan, Universitas Islam Malang \\ ${ }^{3}$ Fakultas Agama Islam, Universitas Islam Malang \\ ${ }^{4}$ Fakultas Teknik, Universitas Islam Malang \\ ${ }^{5}$ Fakultas Ekonomi dan Bisnis, Universitas Islam Malang \\ ${ }^{6}$ Fakultas Peternakan, Universitas Islam Malang
}

Korespondensi email: asmaniyah@unisma.ac.id

\begin{abstract}
ABSTRAK
Desa adalah sumber data paling akurat untuk pencarian data kependudukan. Untuk itu, cara pengumpulan data penduduk, pengisian data dalam format, pengolahan data hingga penyajian informasi data kependudukan kepada masyarakat harus dilakukan secara efektif dan efisien agar informasi yang tersampaikan dapat dengan cepat dan akurat. Kegiatan ini dilakukan dalam 3 tahapan yakni survey; implementasi kegiatan; dan evaluasi kegiatan. Survey di lakukan di Balai Desa Putat Lor, Kecamatan Gondang Legi, Kabupaten Malang. Tim melakukan pendampingan pengurusan kembali username dan password website Desa Putat Lor. Dan hingga kegiatan KKN selesai dilakukan proses pengurusan masih berjalan. Dalam kegiatan ini juga dilakukan kegiatan memperbaharui software-software utama untuk layanan administrasi; desa seperti Microsoft Office, Microsoft Power Point, Microsoft Excel. Dengan tema Digitalisasi Desa untuk Meningkatkan Kualitas Layanan dan Informasi Desa Putat Lor sebagai program kerja dari tim KKN kelompok 74 tahun 2020 yang memiliki tujuan mengubah proses pengurusan dan layanan administrasi di Desa Putat Lor menjadi lebih baik kualitasnya dan informasi tentang Desa Putat Lor lebih mudah dicari oleh masyarakat luas dengan memperbaharui perangkat lunak/sotfwar;e dan mengakseskan situs website khusus untuk memaparkan Desa Putat Lor dan potensi-potensinya.
\end{abstract}

Kata Kunci: digitalisasi; layanan; desa putat lor.

\section{PENDAHULUAN}

Desa adalah sumber data paling akurat untuk pencarian data kependudukan. Untuk itu, cara pengumpulan data penduduk, pengisian data dalam format, pengolahan data hingga penyajian informasi data kependudukan kepada masyarakat harus dilakukan secara efektif dan efisien agar informasi yang tersampaikan dapat dengan cepat dan akurat. Masyarakat desa sangat mengharapkan adanya digitalisasi pelayanan dan informasi kependudukan (Ardhana, 2019).

Digitalisasi dapat diartikan sebagai sebuah proses menyimpan seluruh sifat dan informasi dari teks, suara, gambar, atau multimedia dalam sebuah string elektronik dari nol dan satu bit (Wuryanta, 2004). Digitalisasi memungkinkan merubah segala sesuatu menjadi bentuk yang bisa disimpan di berbagai media digital, seperti compact disc, hard 
disc, serta flash disc, dan bisa ditransfer ke berbagai tempat di seluruh dunia dengan hanya memakan waktu yang sangat singkat melalui jaringan telekomunikasi yang berupa internet (Arifin et al., 2020). Kehadiran internet yang telah mencapai hampir keseluruhan wilayah Indonesia, telah berdampak pada kehidupan masyarakat. Melalui internet masyarakat dapat bertukar informasi tanpa harus bertatap muka (Imaniawan \& Wati, 2017). Penggunaan sistem informasi untuk membantu kinerja pemerintah desa menjadi lebih baik, lebih efisien dan lebih mudah. Dengan didukung oleh kemajuan teknologi informasi yang memungkinkan pengembangan sistem informasi semakin handal (Pardani \& Damayanthi, 2017; Paryanta et al., 2017).

Berdasarkan pengertian tersebut, maka dapat kegiatan digitalisasi berkaitan erat dengan proses menyimpan dan mentransfer informasi secara elektronik melalui media komputer, tanpa mengenal batasan waktu dan tempat. Setiap informasi dapat dengan relatif mudah dan cepat untuk disimpan serta ditransfer ke berbagai tempat di belahan dunia (Wijaya et al., 2013). Hal inilah yang kemudian menjadi potensi yang luar biasa dari media internet. Kegiatan digitalisasi administrasi desa dilakukan dengan tahapan survey atau inventarisasi kondisi digitalisasi yang sudah dilakukan oleh perangkat desa, perumusan masalah, dan upaya pemecahan masalah.

Berbicara mengenai administrasi dan informasi di Desa Putat Lor masih kurang memadai yang ditunjukkan oleh beberapa fakta di lapang antara lain perangkat komputer yang ada di balai Desa Putat Lor masih menggunakan CPU lama dan windows XP serta website daripada Desa Putat Lor hanya tercantum nama dan alamat Desa Putat Lor berada di Kecamatan Gondang Legi Kabupaten Malang tanpa ada keterangan informasi yang lebih detail. Oleh karena itu, Tim KKN-PPM (UNISMA) kelompok 74 tahun 2020 mengangkat tema Digitalisasi Desa sebagai program kelompok. Program ini secara umum bertujuan agar proses pengurusan dan layanan administrasi di Desa Putat Lor lebih baik kualitasnya dan informasi tentang Desa Putat Lor lebih mudah dicari oleh masyarakat luas

\section{METODE}

Kegiatan ini dilakukan dalam 3 tahapan yakni survey, implementasi kegiatan dan evaluasi kegiatan. Survey di lakukan di Balai Desa Putat Lor, Kecamatan Gondang Legi, Kabupaten Malang dengan melakukan silahturahmi kepada seluruh Perangkat Desa Putat Lor yang akan di ambil datanya untuk keperluan keabsahan data. Dalam langkah ini dilakukan analisa tentang potensi implementasi digitalisasi desa di Putat Lor. Tim Kelompok 74 melakukan wawancara terkait optimalisasi penggunaan perangkat lunak untuk layanan masyarakat di desa Putat lor, serta optimalisasi penggunaan website di desa. Setelah survey dilakukan kegiatan implementasi berupa updating program/software layanan administrasi desa yakni pembaharuan software berupa Microsoft Office, Microsoft Power Point, Microsoft Excel dan upaya untuk memperbaharui website desa dengan mencantumkan profil, luas wilayah, letak geografis, sejarah, tingkat perekonomian, jumlah penduduk, dan potensi yang ada di Desa Putat Lor. 


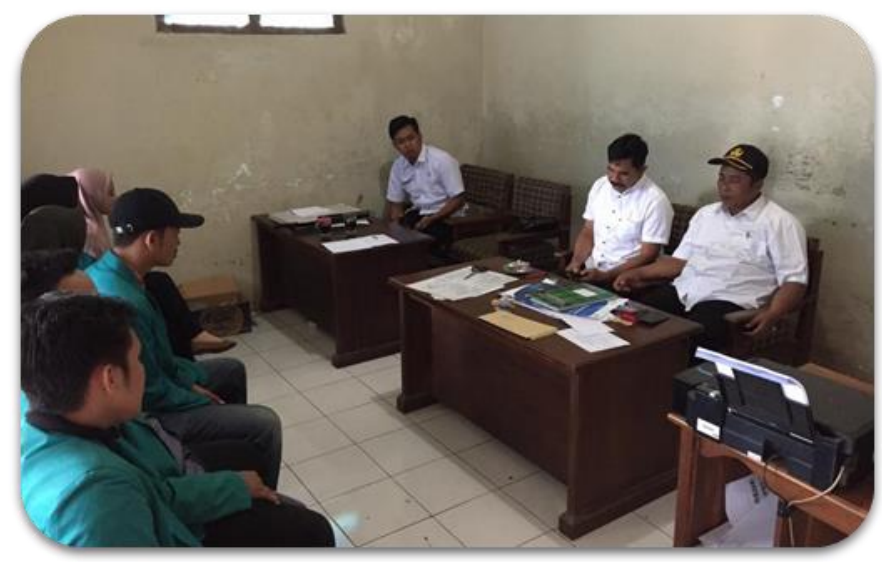

Gambar 1. Survey Software Perangkat Komputer Balai Desa (Sumber : Dok. KKN Putatlor)

\section{HASIL DAN PEMBAHASAN}

Dari hasil survey diketahui bahwa secara umum layanan terhadap kegiatan kemasyarakatan sudah dilakukan dengan perangkat lunak yang ada terutama Microsoft Word, namun untuk website desa saat ini tidak bisa diakses atau diperbaharui tampilannya karena username dan passwordnya tidak lagi diketahui. Untuk itu tim melakukan pendampingan pengurusan kembali username dan password website Desa Putat Lor. Dan hingga kegiatan KKN selesai dilakukan proses pengurusan masih berjalan. Dalam kegiatan ini juga dilakukan kegiatan memperbaharui software-software utama untuk layanan administrasi desa seperti Microsoft Office, Microsoft Power Point, Microsoft Excel.

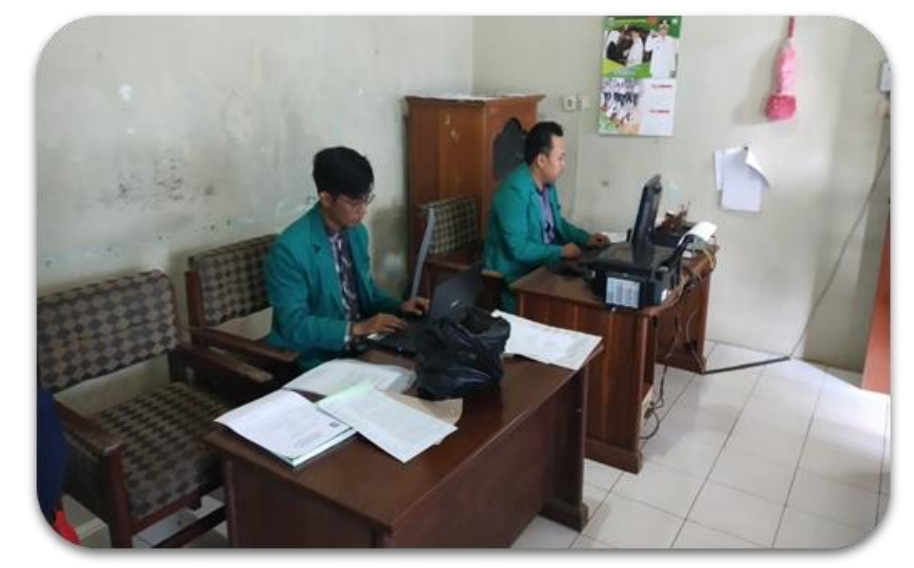

Gambar 2. Penginstalan Software Komputer Balai Desa (Sumber : Dok. KKN Putatlor)

Dari hasil observasi juga diketahui bahwa masyarakat Desa Putat Lor sangat membutuhkan digitalisasi desa. Maka dari hasil pelaksanaan kegiatan "Digitalisasi Desa" kami mampu mendorong masyarakat dan perangkat desa yang sebelumnya jarang sekali mengetahui informasi tentang desa mereka sendiri maupun kurang tahunya tentang software terbaru yang dapat membantu dalam sistem administrasi desa. Setelah kami melakukan program kerja yang telah disetujui oleh masyarakat dan perangkat Desa Putat Lor, sampai saat ini masyarakat dan perangkat desa sudah mulai mengetahui akan hal-hal tersebut.

Dan juga agar masyarakat secara luas dapat mengakses informasi mengenai Desa Putat Lor melalui internet maka Tim KKN kelompok 74 Desa Putat Lor melakukan update informasi pada website Wikipedia Desa Putat Lor dan dapat diakses melalu situs https://id.wikipedia.org/wiki/Putat_Lor,_Gondanglegi,Malang. Disini kami telah 
mencantumkan profil, luas wilayah, letak geografis, sejarah, tingkat perekonomian, jumlah penduduk, dan potensi yang ada di Desa Putat Lor. Sehingga masyarakat dan juga perangkat Desa Putat Lor akan lebih mudah jika ingin mengetahui informasi tentang desa.

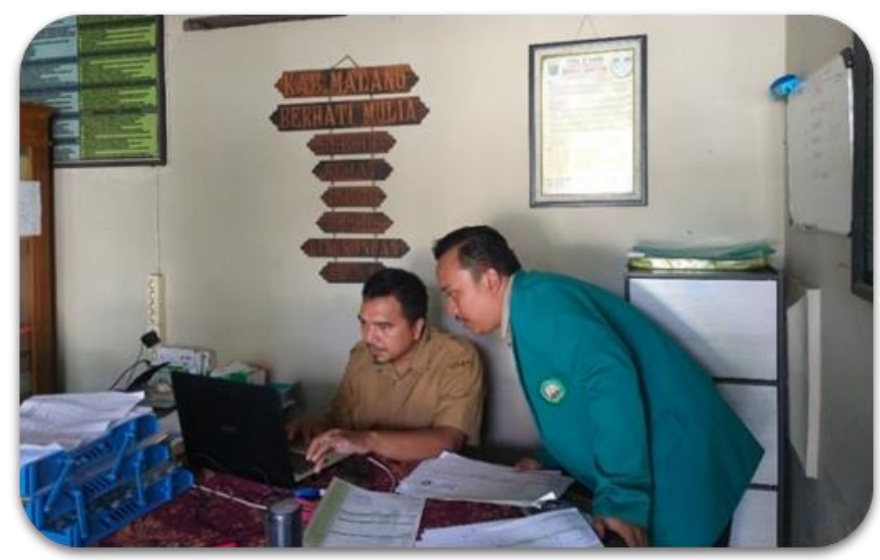

Gambar 3. Menunjukan Hasil Website kepada Perangkat Desa (Sumber: Dok. KKN Putatlor)

Setelah kami dari tim KKN kelompok 74 menyelesaikan program kerja, secara umum respon perangkat desa terhadap kegiatan ini cukup baik dan cukup puas. Meskipun saat awal menggunakan software microsoft yang baru masih sedikit bingung dengan cara kerjanya tetapi kami telah memberikan penyuluhan bagaimana cara kerja microsoft yang baru. Kemudian untuk pembaharuan website, perangkat desa maupun masyarakat umum memberikan respon cukup puas, karena adanya website ini, masyarakat umum pun juga bisa mengetahui tentang profil Desa Putat Lor dengan beserta potensi-potensinya. Harapannya kegiatan seperti ini dapat terus dilanjutkan sehingga keinginan untuk mewujudkan kemajuan Desa Putat Lor yang informatif dan memiliki layanan digital berkualitas dapat diwujudkan.

\section{KESIMPULAN}

Dari kegiatan yang telah kelompok 74 laksanakan terdapat beberapa kesimpulan sebagai berikut (1) Perangkat lunak antara lain Microsoft Office, Microsoft Power Point, Microsoft Excel dengan versi terbaru sangat penting teruatama untuk layanan administrasi Desa Putat Lor; (2) Pengaksesan dan pembaharuan website yang mencantumkan profil, luas wilayah, letak geografis, sejarah, tingkat perekonomian, jumlah penduduk, dan potensi yang ada di Desa Putat Lor sangat diperlukan guna untuk memudahkan masyarakat yang ingin mengetahui mengenai Desa Putat Lor; (3) Dengan tema Digitalisasi Desa untuk Meningkatkan Kualitas Layanan dan Informasi Desa Putat Lor sebagai program kerja dari tim KKN kelompok 74 tahun 2020 yang memiliki tujuan mengubah proses pengurusan dan layanan administrasi di Desa Putat Lor menjadi lebih baik kualitasnya dan informasi tentang Desa Putat Lor lebih mudah dicari oleh masyarakat luas dengan memperbaharui perangkat lunak/sotfware dan mengakseskan situs website khusus untuk memaparkan Desa Putat Lor dan potensi-potensinya.

\section{UCAPAN TERIMA KASIH}

Ucapan terima kasih disampaikan kepada LPPM UNISMA yang memberikan kesempatan kepada kelompok 74 untuk melakukan kegiatan KKN di desa Putat Lor, Gondang legi Kabupaten Malang. 


\section{DAFTAR RUJUKAN}

Ardhana, V. Y. P. (2019). Website Based Village Population Data Information System Sistem Informasi Data Kependudukan Desa Berbasis Web. SainsTech Innovation Journal, 2(2), 1-5. http://jkqh.uniqhba.ac.id/index.php/sij/article/view/99

Arifin, Z., Budi Wahono, B., Prihatmoko, D., \& Riyoko, S. (2020). Inovasi Peningkatan Hasil Tangkapan Ikan Produk Unggulan Daerah oleh Nelayan Purse Seine Menggunakan Teknologi GPS. Jurnal Inovasi Hasil Pengabdian Masyarakat (JIPEMAS), 3(1), 54-62. https://doi.org/10.33474/jipemas.v3i1.4779

Imaniawan, F. F. D., \& Wati, F. F. (2017). Sistem Informasi Administrasi Kependudukan Berbasis Web Pada Desa Bogangin Sumpiuh. Indonesian Journal on Networking and Security, 7(3), 1-9. https://doi.org/10.2311/ijns.v7i3.1516

Pardani, K. K., \& Damayanthi, I. G. A. E. (2017). Pengaruh Pemanfaatan Teknologi, Partisipasi Pemakai, Manajemen Puncak Dan Kemampuan Pemakai Terhadap Efektivitas Sistem Informasi Akuntansi. E-Jurnal Akuntansi, 19(3), 2234-2261. https://ojs.unud.ac.id/index.php/Akuntansi/article/view/29964

Paryanta, Sutariyani, \& Susilowati, D. (2017). Sistem Informasi Administrasi Kependudukan Berbasis Web Desa Sawahan. IJSE - Indonesian Journal on Software Engineering, 3(2), 77-81. https://doi.org/10.31294/ijse.v3i2.2980

Wijaya, E., Anggraeni, R., \& Bachri, R. (2013). Desa Digital: Peluang untuk Mengoptimalkan Penyebarluasan Peraturan Perundang-undangan di Indonesia. Jurnal Dinamika Hukum, 13(1), 75-88. https://doi.org/10.20884/1.jdh.2013.13.1.158

Wuryanta, A. E. W. (2004). Digitalisasi Masyarakat: Menilik Kekuatan dan Kelemahan Dinamika Era Informasi Digital dan Masyarakat Informasi. Jurnal Ilmu Komunikasi, 1(2), 131-142. https://doi.org/10.24002/jik.v1i2.163 